\title{
A SHORT SPINAL CORD IN THE TOAD
}

\author{
W. M. SMALLWOOD \\ Contributions from the Zoological Laboratory, Syracuse University, \\ C. W. Hargitt, Director \\ TWO FIGURES
}

While studying the nervous system of anura in our beginning zoology this fall, I noticed one specimen having most of the neural canal empty save for some nerves. On closer examination, it was seen that the regular ten pairs of nerves were present with their usual distribution. In each intervertebral space a pair of nerves left the neural canal. The specimen was set aside for further study.

When the central nervous system was removed entire, it was readily seen that all of the parts were present and normal except the length of the spinal cord. The letter $\mathrm{X}$ in figure 1 indicates the position of the sacral vertebra and the beginning of the urostyle into which the flium terminale of the spinal cord normally penetrates for a varying distance. This makes the length of the spinal cord less than one-half what it should be and was in all the others examined. During the past ten years I have had opportunity to examine more than 2000 such dissections and this is the first case of such a marked shortening.

Sections of the cord were made by using the Weigert stain and the general results are shown in figure 2. This is a cross section through the region where the seventh, eighth and ninth nerves left the stub of the cord. The following summary shows the more important modifications:

First. The neurocoele is not in the center of the section but pushed ventrally.

Second. The gray substance occupies a greater proportion of the total area in this cross section than in a spinal cord of normal length for anura.

Third. The dorsal gray commissure is greatly enlarged.

Fourth. The dorsal column is nearly double the normal size.

Fifth. There is a small funicular region.

Following Herrick's ${ }^{1}$ classification of the somatic sensory into exteroceptive (pain, touch, heat) and proprioceptive (muscle sense); there is an interesting structural differentiation in the region illustrated by this section. The numerous exteroceptive fibers mostly end

${ }^{1}$ Herrick, C. J. Introduction to Neurology, 1915, p. 132. 
in the dorsal column but in this region three nerves enter close together instead of each pair being separated by a vertebra. In order to be able to take care of the large amount of stimuli coming in over these three nerves, the profound changes mentioned above has taken place.
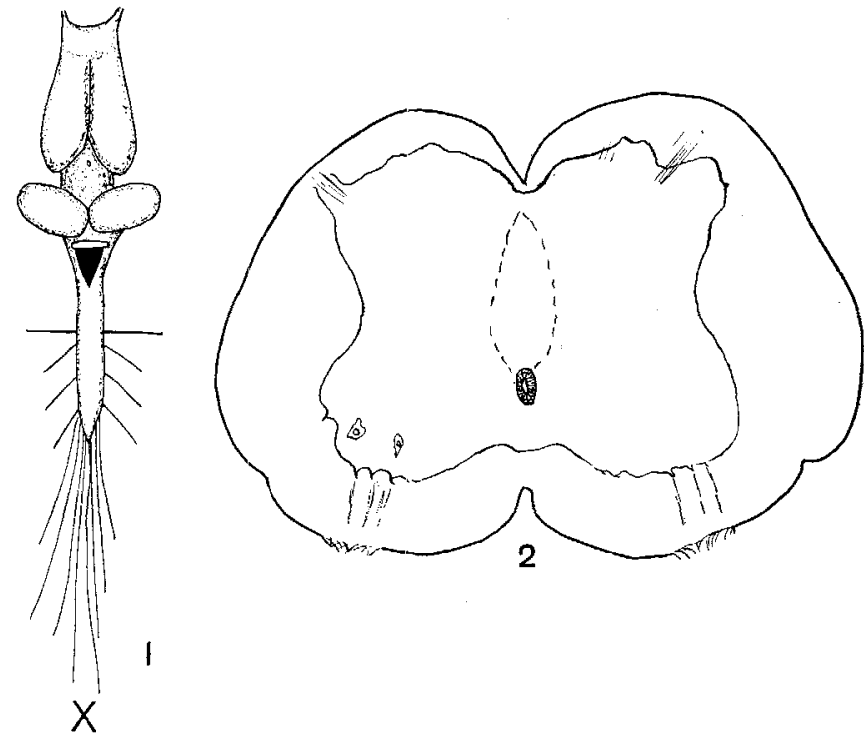

Fig. 1 Short spinal cord in a toad. The letter $\mathrm{X}$ indicates the position of the sacral vertebra and the beginning of the urostyle.

Fig. 2 Camera lucida drawing of cross section of spinal cord of toad through stub of cord. The area outlincd with dashes is the dorsal gray commissure. 